\title{
High rate of caesarean section in cases of intrauterine fetal demise in a low resource setting: Why?
}

\author{
Shivani Kothiyal ${ }^{1 *}$, Anjoo Agarwal², Vinita Das², Amita Pandey², Smriti Agarwal²
}

\begin{abstract}
${ }^{1}$ Department of Obstetrics and Gynecology, Guru Teg Bahadur Hospital, Dilshad Garden, New Delhi, India
${ }^{2}$ Department of Obstetrics and Gynecology, King George's Medical University, Lucknow, Uttar Pradesh, India
\end{abstract}

Received: 13 July 2018

Accepted: 06 August 2018

\section{*Correspondence:}

Dr. Shivani Kothiyal,

E-mail: skothiyal40@gmail.com

Copyright: () the author(s), publisher and licensee Medip Academy. This is an open-access article distributed under the terms of the Creative Commons Attribution Non-Commercial License, which permits unrestricted non-commercial use, distribution, and reproduction in any medium, provided the original work is properly cited.

\begin{abstract}
Background: Stillbirth as an obstetric complication is emotionally devastating for the women as well as the clinician and having a caesarean section for stillbirth is even more catastrophic. The aim of the present research was to study the indications of caesarean section in women with intrauterine fetal demise in a low resource setting.

Methods: This was an observational study for assessing the indication of caesarean section among 222/ 550 stillbirths from June 2013 to May 2014 in a tertiary care teaching hospital of North India. 7024 births occurred in the institution over a period of 1 year out of which 550 were stillbirths. Stillbirths which weighed over 500 grams were included in the study. Details of women with intrauterine fetal demise in which caesarian section was done were noted and analyzed.

Results: Out of 550 stillbirths, 222 women underwent caesarean section. Rate of caesarean section among women with stillbirth was $40.36 \%$. Placenta previa (23.87\%), Rupture uterus (22.1\%), obstructed labour (10.8\%), transverse lie $(9.45 \%)$, failed induction $(7.20 \%)$, massive abruption $(5.86 \%)$, non-progress of labour $(5.40 \%)$, eclampsia/preeclampsia related causes $(4.95 \%)$, acute fetal distress $(4.95 \%)$, were leading indications of caesarean sections. Out of 222 women, $162(73 \%)$ women had anaemia $(\mathrm{Hb}<11 \mathrm{~g} \%)$. Severe anaemia (haemoglobin less then $7 \mathrm{gm} / \mathrm{dl})$ was present in 51 cases $(23 \%)$.

Conclusions: Caesarean section done for intrauterine death in present study were mostly inevitable. Reducing intrapartum stillbirths by improving essential obstetric services will ultimately result in reducing caesarean section rates in stillbirths in developing countries. Further studies are needed both in developing and developed countries to strategize the management of intrauterine dead fetus to prevent such high rate of caesarean section.
\end{abstract}

Keywords: Caesarean section, Intrauterine fetal demise, Stillbirths

\section{INTRODUCTION}

Stillbirth as an obstetric complication is emotionally devastating for the women as well as the clinician and having a caesarean section for stillbirth is even more catastrophic. The fetal death itself does not constitute an indication for cesarean section, therefore the surgery should be reserved for specific conditions, since it increases maternal morbidity without any fetal advantage. ${ }^{1,2}$ Vaginal delivery should be the ideal choice for women for intrauterine fetal deaths but in certain conditions caesarean section is the only option. In general, vaginal delivery is preferable to caesarean section, as maternal risk minimisation is the main priority when fetal welfare is no longer an issue. ${ }^{3-5}$ In present study 550 stillbirths occurred over a period of 1 year in our hospital, out of which 222 underwent caesarean section. Rate of caesarean section was very high 
$(40.36 \%)$ as compared to the acceptable WHO criteria of $10-15 \% .{ }^{6}$ Hence the study was performed to know the indications of caesarean section among 222 out of 550 stillbirths that occurred over a period of one year in present institute.

\section{METHODS}

This was an observational study conducted at Queen Mary Hospital in the Department of Obstetrics and Gynecology, King George's Medical University, Lucknow, India from June 2013 to May 2014. Hospital allowed booked, Un-booked and emergency cases. The hospital caters referrals from rural, semi-urban and urban areas. Queen Mary hospital is one of the busiest hospitals in Northern India in state of Uttar Pradesh, which is one of the most backward states of India. Outcome of all deliveries during this period was noted. All fetus weighing more than $500 \mathrm{~g}$ and showing no signs of life after delivery were classified as still births.

During the 12 months of study that is from June 2013 to May 2014, 7024 deliveries occurred in the hospital. Out of 7024 deliveries, 550 were stillbirths. 222 women with intrauterine fetal death with fetus weighing more than 500 grams underwent caesarean section which were included in the study. Women with intrauterine fetal death which underwent vaginal delivery were excluded from the study.

All 222 females who underwent caesarean section were interviewed after informed consent. Questions regarding personal information like name, age, husband's age, admission number and date of admission, residential address and whether residing in a rural or urban area, socioeconomic status, religion, height, weight, BMI, literacy of husband and wife, occupation of husband and wife, history of any previous stillbirths were asked, and answers noted.

History of folic acid in first trimester and history of iron/calcium intake was taken. Detailed obstetric history was taken. History of multiple pregnancy, history of previous caesarean section, number, time and place of all the antenatal visits were noted. At time of admission of patient with IUD, LMP and EDD was noted. In case of unknown LMP gestational age was classified in terms of preterm, term and post term.

Vitals were taken, and relevant investigations were done. Anemia status with free haemoglobin estimation test was done for all 222 females. Blood pressure with dipstick urine albumin test was done for all patients, detailed general physical and obstetric examination was done. Ultrasounds if available were noted in detail.

Details regarding fundal height, liquor assessment, presentation and fetal heart was noted via obstetric examination. History of bleeding, reduced fetal movements, fever, leaking, foul smelling discharge, trauma and convulsions were asked with leading questions. Time of onset of labour, time of delivery, total duration of labour was noted. NST/CTG records if available and indication of caesarean was noted. Delivery details with fetal weight, sex and birth weight and complication present in this pregnancy was assessed and recorded for study.

\section{RESULTS}

During the 12 months of study that is from June 2013 to May 2014, 7024 deliveries occurred in the hospital. Out of 7024 deliveries, 550 were stillbirths. Out of 550 cases of stillbirth, 222 women underwent caesarian section. Out of 222 cases, 211 cases already had an intrauterine dead fetus while 11 cases came with acute fetal distress with a dipping fetal heart and immediately were taken for caesarean section to save the fetus but ultimately resulted in stillbirth upon delivery which was unfortunate.

Rate of caesarean section among women with stillbirth was $40.36 \%$. Mean age of the women was 28.36 (Range 16- 40 Years), 109 cases had mother's age 30 years or above. $149(67.1 \%)$ women were from rural areas whereas $73(32.9 \%)$ were from urban areas. 181 cases $(81.6 \%)$ were referred from other hospitals, while $18.4 \%$ came directly to hospital. 22 women were grand multipara $(\geq 5)$ (Table 1). 48 women had previous LSCS, 8 women had history of stillbirth in previous pregnancy.

Table 1: Distribution of cases according to parity.

\begin{tabular}{|lll|}
\hline Parity & No. of patients & Percentage \\
\hline >G5 & 22 & 09.9 \\
\hline G4 & 35 & 15.7 \\
\hline G3 & 40 & 18.0 \\
\hline G2 & 45 & 20.3 \\
\hline G1 & 80 & 36.0 \\
\hline
\end{tabular}

Among indications of caesarean section among stillbirths, Antepartum Hemorrhage \{Placenta previa (53 cases) and Abruption (13 cases) $\}$ was the leading cause of caesarian section with total of 66 cases $(29.73 \%)$.

Rupture uterus was present in $49(22.1 \%)$ cases. Out of 49 cases of rupture uterus, previous caesarean scar was present in 16 cases. Obstructed labor was indication in 24 cases $(10.81 \%)$. Malpresentation (transverse lie) in 21 $(9.45 \%)$, failed induction in $16(7.2 \%)$, and non-progress of labor was indication in $12(5.40 \%)$ cases. Preeclampsia and antepartum eclampsia related causes was indication of caesarian section in $11(4.95 \%)$ cases while in $11(4.95 \%)$ cases acute fetal distress was the indication which resulted in a stillbirth fetus upon delivery. Inadequate pelvis with/without previous caesarian section scar was indication of caesarean in 6 cases $(2.7 \%)$. Chorioamnionitis with non-progress of labor was indication in 3 cases while arrest of 2 nd stage of labor, previous 2 LSCS, breech with previous caesarian with scar tenderness contributed to 1 case each (Table 2). 80 
primipara women underwent caesarean section. 27/222 had APH as an indication. 14 had rupture uterus. Failed induction in 9 , obstructed labour and transverse lie in 7 cases each, NPOL in 6, acute fetal distress in 5 cases was indication of caesarean section. Severe preeclampsia with failed induction in 2 cases while Antepartum eclampsia with NPOL, chorioamnionitis with NPOL, inadequate pelvis was indication in 1 case each (Table 1).

Table 2: Indications of caesarean sections among 222/550 stillbirths.

\begin{tabular}{|lll|}
\hline Indications & $\begin{array}{l}\text { No. of } \\
\text { patients }\end{array}$ & Percentage \\
\hline $\begin{array}{l}\text { Placenta previa with active } \\
\text { bleeding }\end{array}$ & 53 & 23.87 \\
\hline Rupture uterus & 49 & 22.07 \\
\hline Obstructed labour & 24 & 10.81 \\
\hline Transverse lie & 21 & 9.45 \\
\hline Failed induction & 16 & 7.20 \\
\hline $\begin{array}{l}\text { Abruption (massive) } \\
\text { Non-progress of labour }\end{array}$ & 13 & 5.86 \\
\hline $\begin{array}{l}\text { Antepartum eclampsia and } \\
\text { pre-eclampsia related }\end{array}$ & 12 & 5.40 \\
\hline $\begin{array}{l}\text { Failed induction with severe } \\
\text { pre-eclampsia }\end{array}$ & 6 & 4.95 \\
\hline $\begin{array}{l}\text { Antepartum eclampsia with } \\
\text { non-progress of labour }\end{array}$ & 5 & \\
\hline $\begin{array}{l}\text { Acute fetal distress } \\
\text { Inadequate pelvis with } \\
\text { previous LSCS }\end{array}$ & 11 & 4.95 \\
\hline $\begin{array}{l}\text { Chorioamnionitis with non- } \\
\text { progress of labour }\end{array}$ & 3 & 2.70 \\
\hline $\begin{array}{l}\text { Arrest of 2 } \\
\text { nd stage of labour }\end{array}$ & 1 & 1.35 \\
\hline $\begin{array}{l}\text { Previous 2 LSCS } \\
\text { Breech with previous LSCS } \\
\text { with scar tenderness }\end{array}$ & 1 & 0.45 \\
\hline
\end{tabular}

Out of total of 222 caesarian, there were 224 stillbirths. 3 twin pregnancies with 5 stillbirths plus 1 live. Out of 224, 96 females, 127 male fetuses and 1 was ambiguous.

Table 3: Distribution of $162 / 2221$ cases according to the severity of Anaemia (ICMR)*.

\begin{tabular}{|lll|}
\hline Anaemia & Range $(\mathrm{gm} / \mathrm{dl})$ & No. of patients \\
\hline Mild & $10-10.9$ & 32 \\
\hline Moderate & $9.9-7$ & 79 \\
\hline Severe & $6.9-4$ & 42 \\
\hline Very severe & $<4$ & 09 \\
\hline
\end{tabular}

*ICMR- Indian Council of Medical Research; ${ }^{1} 60$ women did not have anaemia.

Among 222 caesarian section, anemia was the most common associated complication present in 162 out of 222 cases $(73 \%)$ (Table 3 ). Severe anemia criteria taken as hemoglobin less than $7 \mathrm{gm} / \mathrm{dl}$ as per ICMR was present in 51 patients. Pre-eclampsia (severe and nonsevere) was associated in 42 cases (18.9\%). Mal- presentation (transverse lie) was present in 28 (12.6\%) cases. Intrauterine growth restriction was present in 16 cases (7.2\%). Pre-term premature rupture of membranes/premature rupture of membranes was present in 7 cases. Preterm labor present in 5 cases. Thyroid disorders present in 4, overt diabetes in 4, gestational diabetes mellitus present in 2 and uterine anomaly present in 2 cases. Infections was present in 2 cases, one with typhoid and another patient with dengue fever.

\section{DISCUSSION}

Caesarean section for a patient with intrauterine fetal demise in our study were mostly for maternal indications but caesarean for an acute fetal distress which resulted in stillbirth was an unfortunate event. 222 out of 550 stillbirths undergoing caesarian section is an alarmingly high number. ${ }^{6}$ Rate of caesarean section among women with stillbirth was $40.36 \%$.

Caesarean section rates are usually high in a tertiary care hospital in India. ${ }^{7-10}$ The caesarian section rates of our institute are high due to excessive referrals of complicated cases from rural districts and majority of patients are either pregnant women with ruptured uterus, obstructed labor and hemorrhage among others. ${ }^{11}$ Mean age of women in this study was 28.36 (16-40 years). 39 $(17.6 \%)$ patients in this study were above or equal to 35 years of age. Advanced maternal age is associated both with increased risk of stillbirth and increasing rate of caesarian section. ${ }^{12-21}$ Rural residence is associated with increased risk of stillbirth as well as increased risk of caesarean section. ${ }^{22-27}$

Studies assessing the indication of caesarean in intrauterine fetal demise are lacking. Antepartum hemorrhage as the leading cause of caesarean in stillbirth as also been studied in similar study. ${ }^{28}$ Placenta previa leading to stillbirth directly is a tragic event. Timely intervention at the start of bleeding could easily prevent stillbirth but once stillbirth occurs in a bleeding patient caesarean section is the only option left to save mother to prevent maternal morbidity and mortality.

Delayed referrals reaching tertiary hospitals with obstructed labor is a lost cause as many patients reach with an intrauterine dead fetus or rupture uterus leading to high maternal morbidity as well as mortality which could have been easily avoided by timely intervention. ${ }^{29-}$

${ }^{32}$ Malpresentation as indication of caesarian also studied in similar study. ${ }^{28}$ In some indications like obstructed labour and malpresentation, abdominal deliveries could be reduced by more destructive operations. ${ }^{28}$ Timely diagnosis and external version may lead to decrease in this indication. As specified earlier delayed referrals with patients in advanced labor; such techniques are difficult to be done. Destructive operations are a lost art now and trying them without proper expertise may lead to increased maternal morbidity. ${ }^{33}$ Caesarean done for acute fetal distress which resulted in stillbirth upon delivery 
was an unfortunate event. ${ }^{28}$ Although patient was immediately taken up for caesarean section to give a benefit of doubt to save the dipping fetal heart, still it resulted in stillbirth which is an unfortunate event both for women and the clinician. Caesarean section can be avoided if criteria are met for instrumental delivery. Stage of labor is important factor on which instrumental delivery vs caesarean section is decided.

In the study 80 primipara women underwent caesarean sections that is $36 \%$. Such high number is a worrisome matter as the women did not even has a live birth. Implications of caesarean section in primi-parous patients has been well studied. Prior CS has been identified by several authors to be associated with an increased risk of poor placentation indicating an increased chance of placental abruption in a subsequent pregnancy. ${ }^{34-36} \mathrm{~A}$ similar magnitude of risk was identified for placenta previa. ${ }^{35,36}$ Placenta accreta recurs in approximately a third of subsequent pregnancies and is a risk factor for massive obstetric hemorrhage and hysterectomy in the index pregnancy. ${ }^{37-39}$ Several large population studies have identified prior $\mathrm{CS}$ as a risk for maternal ICU admission, hysterectomy, transfusion, cardiac and renal problems in a woman's next pregnancy. ${ }^{40,41}$ A prior cesarean birth is also associated with a well-documented risk of uterine rupture following labor in a subsequent pregnancy. ${ }^{42}$ All the above risk factors plus studies done which report increased rates of intervention and iatrogenic adverse outcomes such as prematurity, emergency caesarean section and post-partum haemorrhage in pregnancies subsequent to stillbirth is a matter of big concern. ${ }^{43-46}$ Studies are needed to address this issue and guideline for management of pregnancy subsequent to a stillbirth delivery should be available.

\section{CONCLUSION}

Caesarean sections done for these 222/550 stillbirths seemed to be inevitable. Further studies are needed both in developed and developing countries to strategize the management of intrauterine dead fetus to prevent such high rate of caesarean section.

\section{ACKNOWLEDGMENTS}

Authors would like to thank Department of Obstetrics and Gynaecology, King George Medical University, Lucknow.

\section{Funding: No funding sources}

Conflict of interest: None declared

Ethical approval: Not required

\section{REFERENCES}

1. Brazil. Ministry of Health. Secretary of Health? policies. Department of Strategic Policy Management. Technical area of women's health. High risk gestation technical Manual. $3^{\text {rd }}$ edition.
2. ACOG Practice Bulletin No. 102: management of stillbirth. Obstet Gynecol. 2009;113(3):748-61.

3. Queensland Maternity and Neonatal Clinical Guideline: Stillbirth care. Guideline No MN11.24-V4-R16May 2011. Available at http://www. health.qld.gov.au/qcg/documents/g_still5-0.pdf [link expired; now at https://www.health.qld.gov.au/_data/assets/pdf_file/00 23/143087/g-stillbirth.pdf]

4. Siassakos D, Fox R, Draycott T, Winter RM. Management of late intrauterine fetal death and stillbirth. Royal College of Obstetricians and Gynecologists. 2010; :55-13..

5. Silver RM, Heuser CC. Stillbirth workup and delivery management. Clin Obstetr Gynecol. 2010 Sep 1;53(3):681-90

6. World Health Organisation. Appropriate technology for birth. Lancet. 1985;2(8452):436-7.

7. Manjulatha B, Sravanthi TP. Caesarean section rates in a Teaching Hospital: a ten-year review. IOSR J Dent Med Sci. 2015;14(8):1-5.

8. Gupta M, Garg V. The rate and indications of caesarean section in a teaching hospital at Jaipur, India. Int $\mathbf{J}$ Reprod Contracept Obstet Gynecol. 2017; 6:1786-92

9. Sarma P, Boro RC, Acharjee PS. An analysis of indications of caesarean sections at Tezpur medical college and hospital, Tezpur (a government hospital). Int J Reprod Contracept Obstet Gynecol. 2016; 5:13647.

10. Bhasin SK, Rajoura OP, Sharma AK, Metha M, Gupta $\mathrm{N}$, Kumar $\mathrm{S}$ et al. A high prevalence of caesarean section rate in East Delhi. Indian $\mathrm{J}$ Comm Med. 2007;32(3):222-4.

11. Das V, Kumar N, Kumari V, Agarwal A, Pandey A, Agrawal S. Increasing rates of cesarean section, an upcoming public health problem: an audit of cesarean section in a tertiary care center of North India based on Robson classification. Int J Reprod Contracept Obstet Gynecol. 2017; 6(11):4998-5002.

12. O'leary CM, Bower C, Knuiman M, Stanley FJ. Changing risks of stillbirth and neonatal mortality associated with maternal age in Western Australia 1984-2003. Paediatr Perinatal Epidemiol. 2007 Nov;21(6):541-9.

13. Reddy UM, Ko CW, Willinger M. Maternal age and the risk of stillbirth throughout pregnancy in the United States. American journal of obstetrics and gynecology. 2006 Sep 1;195(3):764-70.

14. Gordon A, Raynes-Greenow C, McGeechan K, Morris J, Jeffery H. Risk factors for antepartum stillbirth and the influence of maternal age in New South Wales Australia: a population based study. BMC Preg Childbirth. 2013 Dec;13(1):12.

15. Flenady V, Middleton P, Smith GC, Duke W, Erwich JJ, Khong TY, et al. Stillbirths: the way forward in high-income countries. Lancet. 2011 May 14;377(9778):1703-17.

16. Association between stillbirth and risk factors known at pregnancy confirmation. JAMA 2011;306(22):24692479.

17. Dulitzki M, Soriano D, Schiff E, Chetrit A, Mashiach S, Seidman DS. Effect of very advanced maternal age on 
pregnancy outcome and rate of cesarean delivery. Obstetr Gynecol. 1998 Dec 1;92(6):935-9.

18. Huang L, Sauve R, Birkett N, Fergusson D, van Walraven C. Maternal age and risk of stillbirth: a systematic review. Canad Medi Asso J. 2008 Jan $15 ; 178(2): 165-72$.

19. Bianco A, Stone J, Lynch L, Lapinski R, Berkowitz G, Berkowitz RL. Pregnancy outcome at age 40 and older. Obstetr Gynecol. 1996 Jun 1;87(6):917-22.

20. Yaniv SS, Levy A, Wiznitzer A, Holcberg G, Mazor M, Sheiner E. A significant linear association exists between advanced maternal age and adverse perinatal outcome. Arch Gynecol Obstet. 2011 Apr 1;283(4):7559.

21. Delbaere I, Verstraelen H, Goetgeluk S, Martens G, De Backer G, Temmerman M. Pregnancy outcome in primiparae of advanced maternal age. Eur J Obstetr Gynecol Reprod Biol. 2007 Nov 1;135(1):41-6.

22. Willinger M, Ko CW, Reddy UM. Racial disparities in stillbirth risk across gestation in the United States. Am J Obstetr Gynecol. 2009 Nov;201(5):469-e1.

23. Akpala CO. Perinatal mortality in a northern Nigerian rural community. J Royal Soc Health. 1993 Jun;113(3):124-7.

24. Aisien AO, Lawson JO, Okolo A. Two years prospective study of perinatal mortality in Jos, Nigeria. Int J Gynaecol Obstet. 2000;71:171-3.

25. Wu Z, Viisainen K, Wang Y, Hemminki E. Perinatal mortality in rural China: retrospective cohort study. BMJ. 2003 Dec 4;327(7427):1319.

26. Abebe FE, Gebeyehu AW, Kidane AN, Eyassu GA. Factors leading to cesarean section delivery at Felegehiwot referral hospital, Northwest Ethiopia: a retrospective record review. Reprod Health. 2015 Dec;13(1):6.

27. Al-Mulhim A. Factors affecting the rate and the indications of primary caesarean section. Bahrain Med Bul. 2001;23(4):160-2.

28. Mukherj J, Kamilya G, Bhattacharyya SK. Caesarean section for the dead baby -an unhappy reality. J Indian Med Asso. 2007 Jun;105(6):316-8.

29. Eden RD, Parker RT, Gall SA. Rupture of the pregnant uterus: a 53-year review. Obstetr Gynecol. 1986 Nov;68(5):671-4.

30. Yap OW1, Kim ES, Laros RK Jr. Maternal and neonatal outcomes after uterine rupture in labor. Am J Obstet Gynecol. 2001 Jun;184(7):1576-81.

31. Arora M, Jindal S, Gupta S. Retrospective study of cases of rupture uterus. Int J Reprod Contracept Obstet Gynecol. 2017;6:1900-4.

32. Aggarwal N, Singla R, Dhaliwal L, Suri V. Audit of emergency obstetric referrals-a pilot study from tertiary care centre of North India. Bangladesh J Obstetr Gynaecol. 2016;30(1):25-9.

33. Gupta U, Chitra R. Destructive operations still have a place in developing countries. Int J Gynaecol Obstet. 1994 Jan;44(1):15-9.
34. Hemminki E. Long term maternal health effects of caesarean section. J Epidemiol Comm Health. 1991 Mar 1;45(1):24-8.

35. Hemminki E. Impact of Caesarean section on future pregnancy-a review of cohort studies. Paediat Perinatal Epidemiol. 1996 Oct;10(4):366-79.

36. Hemminki E, Meriläinenb J. Long-term effects of cesarean sections: ectopic pregnancies and placental problems. Am J Obstetr Gynecol. 1996 May 1;174(5):1569-74.

37. Armstrong CA, Harding S, Matthews T, Dickinson JE. Is placenta accreta catching up with us?. Aus NZ J Obstetr Gynaecol. 2004 Jun;44(3):210-3.

38. Sentilhes L, Kayem G, Ambroselli C, Provansal M, Fernandez H, Perrotin F, et al. Fertility and pregnancy outcomes following conservative treatment for placenta accreta. Hum Reprod. 2010 Sep 10;25(11):2803-10.

39. O'Brien D, Babiker E, O'Sullivan O, Conroy R, McAuliffe F, Geary M, et al. Prediction of peripartum hysterectomy and end organ dysfunction in major obstetric haemorrhage. Eur J Obstetr Gynecol Reprod Biol. 2010 Dec 1;153(2):165-9.

40. Souza JP, Cecatti JG, Faundes A, Morais SS, Villar J, Carroli G, et al. Maternal near miss and maternal death in the World Health Organization's 2005 global survey on maternal and perinatal health. Bulletin of the World Health Organization. 2010;88:113-9.

41. Zwart JJ, Richters JM, Öry F, De Vries JI, Bloemenkamp KW, Van Roosmalen J. Severe maternal morbidity during pregnancy, delivery and puerperium in the Netherlands: a nationwide population-based study of 371000 pregnancies. BJOG: Int J Obstetr Gynaecol. 2008 Jun 1;115(7):842-50.

42. Justus Hofmeyr G, Say L, Metin Gülmezoglu A. Systematic review: WHO systematic review of maternal mortality and morbidity: the prevalence of uterine rupture. BJOG: Int J Obstet Gynaecol. 2005 Sep;112(9):1221-8.

43. Heinonen S, Kirkinen P. Pregnancy outcome after previous stillbirth resulting from causes other than maternal conditions and fetal abnormalities. Birth. 2000 Mar 1;27(1):33-7.

44. Robson S, Chan A, Keane RJ, Luke CG. Subsequent birth outcomes after an unexplained stillbirth: preliminary population-based retrospective cohort study. Aus NZ J Obstetr Gynaecol. 2001 Feb 1;41(1):29-35.

45. Lurie S, Eldar I, Glezerman M, Sadan O. Pregnancy outcome after stillbirth. J Reprod Med. 2007 Apr;52(4):289-92.

46. Black M, Shetty A, Bhattacharya S. Obstetric outcomes subsequent to intrauterine death in the first pregnancy. BJOG: Int J Obstet Gynaecol. 2008 Jan 1;115(2):26974.

Cite this article as: Kothiyal S, Agarwal A, Das V, Pandey A, Agarwal S. High rate of caesarean section in cases of intrauterine fetal demise in a low resource setting: Why?. Int J Reprod Contracept Obstet Gynecol 2018;7:3748-52. 